\title{
EFFECT OF THERMOMECHANICAL TREATMENT ON THE FORMATION OF THE STRUCTURE OF HIGH-STRENGTH Nb- AND Ti-BASED ALLOYS
}

\author{
O. P. Shaboldo ${ }^{1}$, Ya. M. Vitorsky ${ }^{1}$, V. V. Sagaradze ${ }^{2}$, \\ E. G. Volkova ${ }^{* 2}$, N. L. Pechorkina ${ }^{2}$ \\ ${ }^{1}$ TsNIIM OJSC, 8 Paradnaya St., 191014, St. Petersburg, Russia \\ ${ }^{2}$ M.N. Miheev Institute of Metal Physics, Ural Branch of the Russian Academy of Sciences, \\ 18 S. Kovalevskoy St., 620990, Ekaterinburg, Russia \\ *Corresponding author. E-mail: volkova@imp.uran.ru; \\ address for correspondence: 620990, ul. S. Kovalevskaya 18, Ekaterinburg, Russia. \\ Tel.: +7 (343) 37440 54; fax: +7 (343) 3745244.
}

The paper studies the effect of heat treatment conditions on the microstructure of the $\mathrm{LN}-1(\mathrm{Nb}-10 \mathrm{~W}-5 \mathrm{Mo}-1.5 \mathrm{Zr}-0.15 \mathrm{C})$ and TS6 (Ti-10.5Cr-7V-4Mo-3Al-1Zr) alloys. It is shown for the LN-1 alloy that, under specific temperature conditions, a sufficiently high level of plasticity, necessary for subsequent deformation, is realized in the alloy. The structural studies have revealed the formation of finely dispersed niobium-zirconium carbides in the matrix during thermomechanical strengthening with the use of preliminary annealing. It is demonstrated that cold deformation by drawing $(\varepsilon=24 \%)$ of the TS6 alloy leads to the formation of a cellular-band structure with high dislocation density along the cell boundaries. In the process of subsequent aging, the $\beta$-phase disintegrates with heterogeneous isolation of thin $\alpha$-phase plates thus ensuring a considerable increase in the strength characteristics of the alloy.

Keywords: high-temperature niobium alloys, carbides, $\beta$-titanium alloy, cold deformation, aging, $\alpha$-phase, electron microscopy, mechanical properties, strengthening.

DOI: $10.17804 / 2410-9908.2016 .6 .006-016$

\section{References}

1. Shaboldo O.P., Vitorsky Ya.M., Karashtin E.A. Spring materials made of high-temperature niobium- and nickel-based alloys. In: TsNII materialov - 100 let na blago Rossii [Central Research Institute of Materials - 100 Years for the Benefit of Russia]. St. Petersburg, 2012, pp. 125-136. (In Russian).

2. Shaboldo O.P., Vitorsky Ya.M., Karashtin E.A., Vasiliev E.V., Sorokin M.V. Spring materials with special properties made of highly alloyed hard-to-deform thermomechanically hardenable high-strength alloys based on titanium, nickel and niobium. Metalloobrabotka, 2011, vol. 62, no. 2 , pp. 28-35. (In Russian).

3. Savitsky E.M., Dashevskaya O.B. Dispersion hardening in niobium-based alloys. Izvestiya AN SSSR. Metally, 1967, no. 3, pp. 152-158. (In Russian).

4. Bershtein M.L. Termomekhanicheskaya obrabotka metallov i splavov. T. 1. [Thermomechanical Treatment of Metals and Alloys, vol. 1.]. M., Metallurgiya Publ., 1968, 596 p. (In Russian).

5. Khorev A.I. Creating a theory of heat treatment, thermomechanical treatment and texture hardening of promising titanium alloys. Materialovedenie, 2009, no. 4, pp. 28-36. (In Russian).

6. Shaboldo O.P., Vitorsky Ya.M., Karashtin E.A. Creating a spring material based on the TS6 high-strength titanium $\beta$-alloy. In: TsNII materialov - 100 let na blago Rossii [Central Research Institute of Materials - 100 Years for the Benefit of Russia]. St. Peterburg, 2012, pp. 158-168. (In Russian).

7. $\quad$ Friedrich H., Kiese J., Haldenwanger H.-G., Stich A. Titanium in Automotive Applications Nightmare, Vision or Reality. In: Proceedings of the 10th World Conference on Titanium, Hamburg, Germany, 13-18 July, 2003, vol. V, editted by G. Liitjering and J. Albrecht, pp. 3393-3402.

Shaboldo O.P. et al. / Effect of thermomechanical treatment on the formation of the structure of high-strength $\mathrm{Nb}$ - and Ti-based alloys 
http://dream-journal.or"]

8. Kosaka Y., Faller K. Advance of beta titanium alloy TIMETAL LCB in automotive spring applications. Wire Journal International, 2006, vol. 39, no.4, pp. 87-93.

9. Konno T.J., Miura E., Tanaka A., Hanada S. A TEM study on the semicoherent precipitates in Nb-19 \% Mo alloy. Acta Materialia, 2005, vol. 53, iss. 6 pp. 1783-1789. DOI: 10.1016/j.actamat.2004.12.027.

10. Viswanadham R.K., Wert C.A. Precipitation from supersaturated Nb-C solid solutions. Metallurgical transactions, 1974, vol. 5, pp. 123-126.

11. Ivasishin O.M., Markovsky P.E., Allen P.G., Sawakin D.G., Matviychuk Yu.V. Rapid Heat Treatment of TIMETAL-LCB Alloy. In: Proceedings of the 9th World conference on Titanium, vol. 1, Saint-Petersburg, Russia, 7-11 June, 1999. St.-Petersburg, CRISM "PROMETEY" Publ., 1999, pp. 505-512.

12. Bhattacharjee A., Vydehi A. Joshi, Gogia A.K. Microstructure and tensile behavior of a low cost beta alloy. In: Proceedings of the 9th World conference on Titanium, vol. 1, Saint-Petersburg, Russia, 7-11 June, 1999. St.-Petersburg, CRISM “PROMETEY” Publ., 1999, pp. 537-544. 
Подана в журнал: 07.11.2016

УДК 669.293'27:539.25

DOI: $10.17804 / 2410-9908.2016 .6 .006-016$

\title{
ВЛИЯНИЕ ДЕФОРМАЦИОННО-ТЕРМИЧЕСКОЙ ОБРАБОТКИ НА ФОРМИРОВАНИЕ СТРУКТУРЫ ВЫСОКОПРОЧНЫХ СПЛАВОВ НА ОСНОВЕ Nb И Ti
}

\author{
О. П. Шаболдо ${ }^{1}$, Я. М. Виторский ${ }^{1}$, .В. В. Сагарадзе ${ }^{2}$, \\ Е. Г. Волкова ${ }^{2}$, Н. Л. Печеркина ${ }^{2}$ \\ ${ }^{1}$ АО «ЦНИИМ», Санкт-Петербург, Россия \\ ${ }^{2}$ Федеральное государственное бюджетное учреждение науки Институт физики металлов \\ им. М.Н. Михеева Уральского отделения Российской академии наук, \\ 620990, ул. С. Ковалевской, 18, Екатеринбург, Россия \\ *Ответственный автор. Электронная почта: volkova@imp.uran.ru; \\ адрес для переписки: 620990, ул. С. Ковалевской, 18, Екатеринбург, Россия. \\ Тел.: +7 (343) 374-40-54; факс: +7 (343) 374-52-44.
}

В работе исследовано влияние термических обработок на микроструктуру сплавов ЛН-1 (Nb-10W-5Mo-1,5Zr-0,15C) и ТС6 (Ti-10,5Cr-7V-4Mo-3Al-1Zr). Для сплава ЛН-1 показано, что при определенном температурном режиме в сплаве реализуется достаточно высокий уровень пластичности, необходимый для последующей деформации. Структурные исследования выявили формирование мелкодисперсных ниобий-циркониевых карбидов в матрице в процессе термомеханического упрочнения с использованием предварительного отжига. Показано, что холодная деформация волочением $(\varepsilon=24 \%)$ сплава ТС6 приводит к формированию ячеисто-полосовой структуры и высокой плотностью дислокаций по границам ячеек. В процессе последующего старения происходит распад $\beta$-фазы с гетерогенным выделением пластин $\alpha$-фазы малой толщины, что обеспечивает существенное повышение прочностных характеристик сплава.

Ключевые слова: жаропрочные ниобиевые сплавы, карбиды, $\beta$-титановый сплав, холодная деформация, старение, $\alpha$-фаза, электронная микроскопия, механические свойства, упрочнение.

\section{1. Введение}

Деформационно-термическая обработка является одним из наиболее эффективных инструментов формирования структуры и свойств сталей и сплавов. Существует большое количество схем термообработок, разработанных для ниобиевых и титановых сплавов [1-3]. Использование различных способов деформационно-термических обработок является весьма перспективным для создания материалов с широким спектром свойств при низких и высоких температурах, в том числе и для пружинного производства. Наиболее широкое применение для этих целей находят ниобиевые сплавы, например $\mathrm{Nb}-10 \mathrm{~W}-5 \mathrm{Mo}-1,5 \mathrm{Zr}-0,15 \mathrm{C}$ (ЛН-1) и $\beta$ - и псевдо $\beta$-титановые сплавы, например высокопрочный сплав ТС6 (Ti-10,5Cr-7V-4 Mo-3Al-1Zr) $[4,5]$. Высокие характеристики длительной прочности сплава $\mathrm{Nb}-10 \mathrm{~W}-5 \mathrm{Mo}-1,5 \mathrm{Zr}-0,15 \mathrm{C}$ (ЛН-1) обеспечиваются не только за счет высокой температуры плавления ниобия, но и в результате твердорастворного легирования такими тугоплавкими элементами, как молибден (5\%) и вольфрам (10\%). Дополнительное упрочнение сплава достигается в результате дисперсионного твердения с выделением наноразмерной карбидной фазы, для чего в сплав введены углерод (до 0,15 \%) и карбидообразующий цирконий (до 1,5 \%) [6]. Титановые сплавы с термически нестабильной $\beta$-фазой обладают высокой технологической пластичностью в $\beta$-состоянии. Упрочнение $\beta$-сплавов титана при ТМО обеспечивается за счет создания пластической деформацией дефектов кристаллической решетки различного характера, а также в результате распада $\beta$-фазы с выделением мелкодисперсных частиц

Shaboldo O.P. et al. / Effect of thermomechanical treatment on the formation of the structure of high-strength $\mathrm{Nb}$ - and Ti-based alloys 
$\alpha$-фазы в процессе старения. Изучение тонкой структуры в совокупности с исследованием механических свойств сплавов ЛН-1 и ТС6 на различных этапах ТМО является целью настоящей работы.

\section{2. Материалы и методика исследования}

В качестве материала для исследования использовали кованые прутки ниобиевого сплава $\mathrm{Nb}-10 \mathrm{~W}-5 \mathrm{Mo}-1,5 \mathrm{Zr}-0,15 \mathrm{C}$ (ЛН-1) диаметром 6.0 мм, полученные ротационной ковкой при температурах $900-1000{ }^{\circ} \mathrm{C}$ из рекристаллизованной заготовки диметром 18,0 мм. Степень теплой деформации составила $\varepsilon=89 \%$. В исходном состоянии и после отжига определяли механические свойства на растяжение на 5-кратных образцах с диаметром рабочей части 2,0 мм. Испытания проводили на машине Zwick 050. Образцы перед испытаниями отжигали при разных температурах $\left(900-1550{ }^{\circ} \mathrm{C}\right)$ в течение 1 ч в вакуумной печи ЭСКВЭ-1.2.2,5/25-ШМ1. Обработку на твердый раствор (ОТР), закалку и старение проводили на шлифованных прутках диаметром 4,0 мм и длиной 60-80 мм. ОТР в течение 1 ч и закалку от температуры $1850{ }^{\circ} \mathrm{C}$ осуществляли в печи ЭЗСКВЭ-1,2.2,5/20-ШМ1 с закалочной вакуумированной камерой. Двухступенчатое старение образцов по режиму $\left(1000{ }^{\circ} \mathrm{C}, 5\right.$ ч $+1200^{\circ} \mathrm{C}, 5$ ч) проводили в той же печи. Остаточное давление в рабочей зоне печи при всех термообработках составляло $1,3 \times 10^{-3} \mathrm{MПа}$.

Для сплава TC6 (Ti-10,5Cr-7V-4Mo-3Al-1Zr) в качестве исследуемого материала использовали серийно выпускаемые ПАО «Корпорация ВСПО-АВИСМА» горячекатаные механически обработанные прутки из диаметром 8,0 мм. Прутки после предварительной термообработки (закалки) подвергали холодному волочению до диаметра 4,6 мм с промежуточными закалками для снятия наклепа, и финишной закалке от температуры $800{ }^{\circ} \mathrm{C}$. Суммарная степень деформации до финишной закалки составляла $\varepsilon=45 \%$. Закаленный материал подвергали холодному волочению со степенями деформации $\varepsilon=24,0 ; 48,5 ; 60,0$ и 75,0 \%. Старение образцов из проволоки, деформированной со степенью $\varepsilon=24 \%$, проводили при температуре $450{ }^{\circ} \mathrm{C}$. Для реализации упрочняющей термической обработки по схеме «закалка + старение» образцы из закаленной проволоки диаметром 4,6 мм подвергали старению в электропечи при $480{ }^{\circ} \mathrm{C}$. Все закалки осуществляли с использованием электроконтактного нагрева со скоростью $25-50{ }^{\circ} \mathrm{C} / \mathrm{c}$ до температуры $800{ }^{\circ} \mathrm{C}$ с последующим охлаждением на воздухе. Контроль температуры проводили с помощью инфракрасной камеры. Механические свойства сплава определяли на машине Zwick Z 050 на образцах с длиной рабочей части 100 мм (испытывали 3-6 образцов на точку).

Исследование тонкой структуры выполняли на электронном микроскопе JEM 200CX в темном и светлом полях при ускоряющем напряжении 160 кВ. На рентгеновском дифрактометре ДРОН-3,0 в монохроматизированном $\mathrm{CuK}_{\alpha}-$ излучении исследовали фазовый состав анодных осадков, полученных из сплава $\mathrm{Nb}-10 \mathrm{~W}-5 \mathrm{Mo}-1,5 \mathrm{Zr}-0,15 \mathrm{C}$ (ЛН-1) электрохимическим осаждением. Параметр решетки твердого раствора после проведения термообработок определяли ренгтгенографически.

\section{3. Экспериментальные результаты и их обсуждение}

На рис. 1 представлены результаты испытаний на растяжение кованых прутков сплава ЛН-1 в деформированном состоянии и после отжигов при температурах $900-1550{ }^{\circ} \mathrm{C}$. Как видно из представленных графиков, отжиг прутков при температурах $900-1100{ }^{\circ} \mathrm{C}$ приводит к снижению прочностных и упругих свойств и повышению пластических характеристик материала (по сравнению с деформированным состоянием). По данным электронно-микроскопических исследований, исходная полосчато-ячеистая структура кованого прутка практически сохраняется до температуры отжига $1100{ }^{\circ} \mathrm{C}$, однако плотность дислокаций падает. Рост параметра кристаллической решетки твердого раствора в этом диапазоне температур

Shaboldo O.P. et al. / Effect of thermomechanical treatment on the formation of the structure of high-strength $\mathrm{Nb}$ - and Ti-based alloys 
обусловлен выходом из него легирующих элементов (молибдена и вольфрама) с меньшими, чем у ниобия, атомными радиусами.
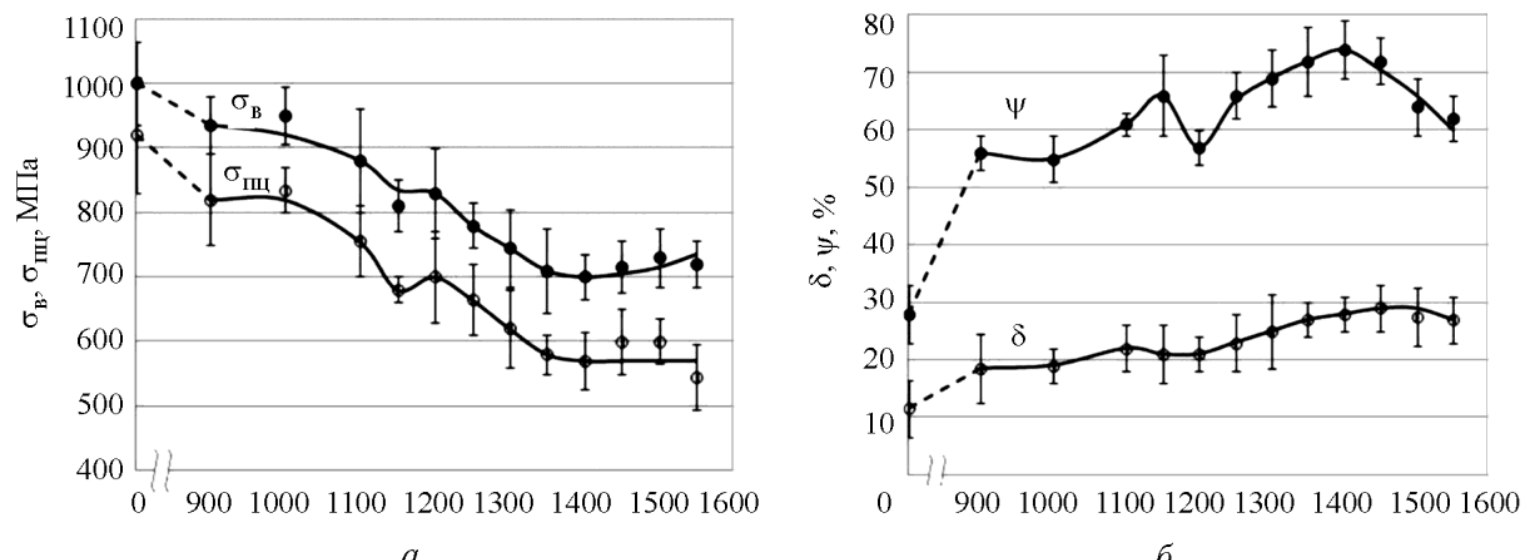

Рис. 1. Влияние температуры отжига на механические свойства кованых прутков из сплава ЛН-1, $\mathrm{T}_{\text {исп }}=20^{\circ} \mathrm{C}: a-$ характеристики прочности; $\sigma-$ характеристики пластичности

Последнее подтверждено результатами электронно-микроскопических исследований и рентгенофазового анализа. Так, если в кованом «втеплую» сплаве ЛН-1 присутствовали устойчивые карбиды ниобия $\mathrm{NbC}(a=4,52 \AA)$, циркония $\operatorname{ZrC}(a=4,63 \AA)$ в количестве 2,58 вес. \%, то после отжига по режиму $1100{ }^{\circ} \mathrm{C}, 1$ ч в сплаве кроме перечисленных фаз обнаружены следы фазы сложных карбидов типа $\mathrm{Me}_{2} \mathrm{C}$, т.е. карбидов ниобия, легированных небольшим количеством молибдена и вольфрама. Общее количество выделившихся фаз возрастает до 2,86 масс. \%. Монотонное изменение механических свойств сплава (снижение прочности и повышение пластичности) незначительно нарушается в диапазоне температур $1100-1200{ }^{\circ} \mathrm{C}$ (рис. 1), что обусловлено перестройкой дислокационной структуры и выделением из твердого раствора второй фазы. Снижение в результате отжигов при температурах 1150 и $1200{ }^{\circ} \mathrm{C}$ параметра решетки твердого раствора, как относительно исходного состояния, так и по сравнению с состояниями после отжигов при более низких температурах, обусловлено активным выходом из твердого раствора атомов углерода и циркония - легирующего элемента с большим, чем у атомов ниобиевой матрицы радиусом $[7,8]$. Выделившаяся в результате отжига при температуре $1150{ }^{\circ} \mathrm{C}$ мелкодисперсная фаза, имеющая гексагональную решетку, идентифицирована как сложнолегированный (в том числе цирконием) карбид типа $\mathrm{Me}_{2} \mathrm{C}$.

Общее количество фаз составляет 3,57 вес. \%. Кроме того, как показали электронномикроскопические исследования, в процессе отжига при температуре $1150^{\circ} \mathrm{C}$ происходит перестройка границ ячеек и существенно снижается плотность дислокаций внутри них, т.е. начинаются (но не завершаются) полигонизационные процессы [1]. В результате формирования при отжиге $\left(1150{ }^{\circ} \mathrm{C}, 1\right.$ ч) такой структуры сплав ЛН-1 обладает следующими механическими свойствами: $\sigma_{\text {в }}=810 \mathrm{MПа;} \sigma_{\text {пц }}=680 \mathrm{MПа;} \delta=21,5 \% ; \psi=65,5 \%$.

Проведение отжига в условиях динамического вакуума при температурах $1200-1550{ }^{\circ} \mathrm{C}$ приводит к насыщению сплава ЛН-1 кислородом и образованию в кованых прутках кислородсодержащих фаз, количество и размеры которых возрастают с повышением температуры отжига. Известно [3], что примеси внедрения $(\mathrm{O}, \mathrm{N})$ тормозят образование при старении после OTP сложного карбида $(\mathrm{NbZr}) \mathrm{C}$, основной упрочняющей фазы в сплавах системы $\mathrm{Nb}-\mathrm{W}-\mathrm{Mo}-\mathrm{Zr}-\mathrm{C}$, забирая цирконий в оксиды и нитриды. Данные фазы в силу своей устойчивости не растворяются полностью при последующем нагреве под закалку $\left(1800-1850{ }^{\circ} \mathrm{C}\right)$ и существенно обедняют твердый раствор легирующими карбидообразующими элементами. Обнаруженные же в сплаве после отжига при более низких температурах $\left(900-1150{ }^{\circ} \mathrm{C}\right)$ фазы типа $\mathrm{Me}_{2} \mathrm{C}$ растворяются при ОТР, обогащая при этом твердый раствор цирконием и углеро-

Shaboldo O.P. et al. / Effect of thermomechanical treatment on the formation of the structure of high-strength $\mathrm{Nb}$ - and Ti-based alloys 
дом. Поэтому их выделение во время технологического отжига не оказывает какого-либо отрицательного влияния на жаропрочные свойства сплава в окончательном термоупрочненном состоянии. В связи с вышеизложенным был выбран промежуточный вакуумный отжиг кованых ниобиевых прутков сплава $\mathrm{Nb}-10 \mathrm{~W}-5 \mathrm{Mo}-1,5 \mathrm{Zr}-0,15 \mathrm{C}$ (ЛН-1) в интервале температур $1100-1150{ }^{\circ} \mathrm{C}$, что обеспечивает повышенную пластичность материала $(\delta=18-25 \%$, $\psi=60-70 \%$ ), незначительное насыщение сплава кислородом и исключает растрескивание и разрушение материала при навивке пружин.

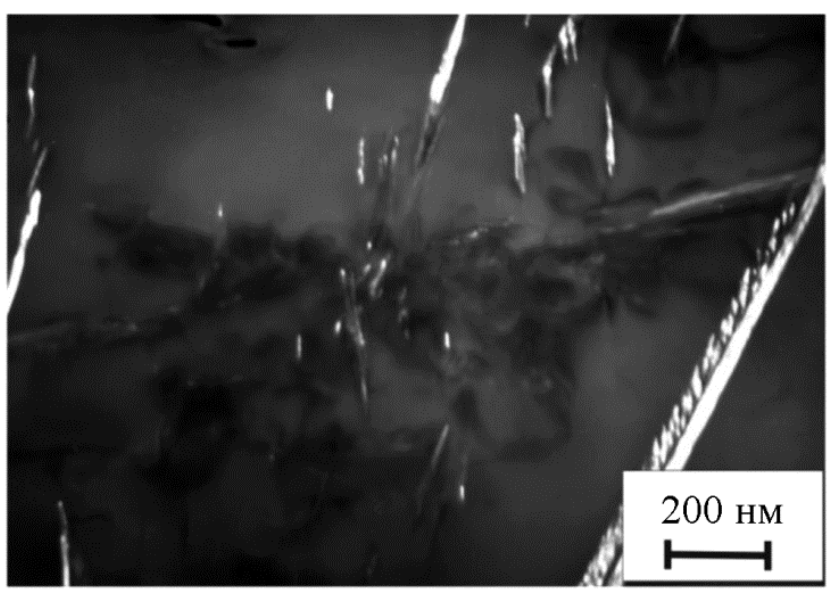

$a$

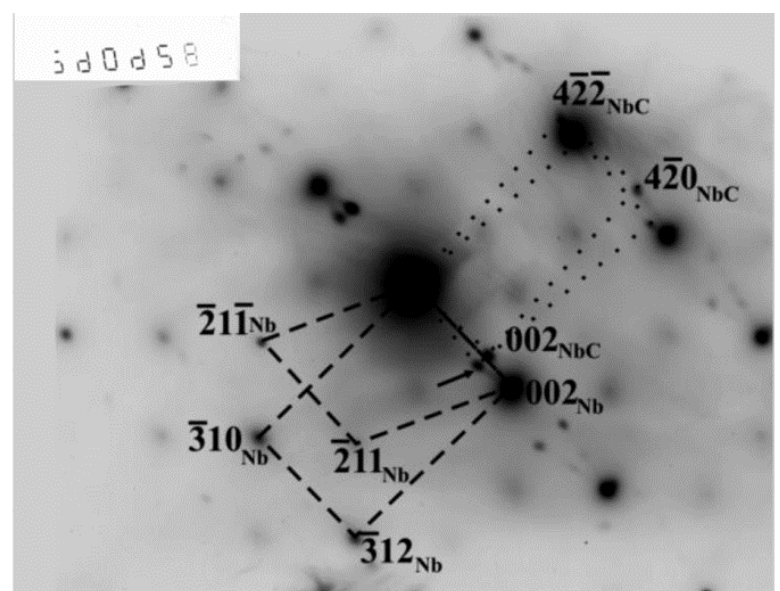

$\sigma$

Рис. 2. Структура (a) и микродифракция (б) сплава ЛН-1 после термоупрочнения по схеме: OTP $\left(1850{ }^{\circ} \mathrm{C}, 1\right.$ ч $)+$ закалка + старение $\left(1000{ }^{\circ} \mathrm{C}, 5\right.$ ч $+1200{ }^{\circ} \mathrm{C}, 5$ ч $) ; a$ - темное поле в рефлексе $002_{\mathrm{NbC}}$ (указано стрелкой), $\sigma$ - картина микродифракции, оси зон $(120)_{\mathrm{NbC}},(130)_{\mathrm{Nb}},(120)_{\mathrm{Nb}}$

Значительный интерес представляет исследование влияния предварительного отжига на структуру закаленного и состаренного сплава $\mathrm{Nb}-10 \mathrm{~W}-5 \mathrm{Mo}-1,5 \mathrm{Zr}-0,15 \mathrm{C}$ (ЛН-1). Выполнен сравнительный анализ структуры образцов из сплава ЛН-1, которые были подвергнуты окончательной обработке по режиму: ОТР $\left(1850{ }^{\circ} \mathrm{C}, 1\right.$ ч), закалка со скоростью охлаждения $50{ }^{\circ} \mathrm{C} / \mathrm{c}$, двухступенчатое старение $\left(1000{ }^{\circ} \mathrm{C}, 5\right.$ ч $+1200{ }^{\circ} \mathrm{C}, 5$ ч) с проведением предварительного отжига при температуре $1150{ }^{\circ} \mathrm{C}(1$ ч) и без него. Результаты исследования структуры после ОТР и закалки показали в обоих случаях наличие в ОЦК матрице мелкодисперсных карбидов типа (NbZr)C размером 10-15 нм. Старение закаленного сплава с предварительным отжигом $\left(1150{ }^{\circ} \mathrm{C}, 1\right.$ ч) и без него привело к формированию различной структуры. В результате двухступенчатого старения образцов без предварительного отжига наблюдается преимущественно гетерогенное образование (в основном на границах зерен и полосчатых субзерен) пластинчатых кристаллов карбида $\mathrm{NbC}$ (рис. 2), что соответствует диаграмме превращений в сплаве ЛН-1 [1] и фазовым диаграммам систем $\mathrm{Nb}-\mathrm{Me}_{\mathrm{IV}}-\mathrm{C}$ и $\mathrm{Nb}-\mathrm{Zr}-\mathrm{C}$ [9, 10]. Часть таких пластин фрагментируется. Наличие тяжей на микродифракции (рис. 2 б) свидетельствует о малой толщине карбидных пластин. На рис. 2 а вблизи границы зерна видны строчечные выделения, которые по межплоскостным расстояниям (111), составляющим около 2,6 А, можно идентифицировать как сложнолегированный карбид типа (NbZr)C. Двухступенчатое старение закаленного от $1850{ }^{\circ} \mathrm{C}$ сплава ЛН-1 (с проведением предварительного отжига при температуре $1150{ }^{\circ} \mathrm{C}, 1$ ч) приводит, напротив, к более гомогенному выделению мелкодисперсных частиц (NbZr)C (рис. 3). По форме эти выделения подобны тонким дискам, что видно по особенностям контраста на светлопольных темнопольных изображениях. При повороте фольги на несколько градусов изображения из пластин толщиной менее 10 нм превращаются в диски диаметром 20-40 нм. На картине микродифракции (рис. 3 б) видны тяжи в направлении [110]. Влияние предварительного отжига на структурно-фазовый состав спла-

Shaboldo O.P. et al. / Effect of thermomechanical treatment on the formation of the structure of high-strength $\mathrm{Nb}$ - and Ti-based alloys 
ва после закалки и старения можно объяснить следующим образом. Как отмечалось выше, выделение второй фазы при температурах предварительного отжига $1100-1150{ }^{\circ} \mathrm{C}$ одновременно с перестройкой дислокационной структуры приводит к равномерному распределению и росту частиц типа $(\mathrm{NbZr}) \mathrm{C}$ и $\mathrm{Me}_{2} \mathrm{C}$, чего еще нет в исходной структуре кованого сплава. При последующем кратковременном высокотемпературном нагреве до $1850{ }^{\circ} \mathrm{C}$ (ОТР) данные частицы растворяются, но матрица не успевает гомогенизироваться и в ней сохраняются равномерно распределенные зоны с повышенной концентрацией циркония и, возможно, углерода. В процессе дальнейшего старения в этих участках гомогенно образуются тонкие диски стабильного карбида типа $(\mathrm{NbZr}) \mathrm{C}$. Можно полагать, что такая структура обеспечит наиболее высокую жаропрочность сплава ЛН-1 при температурах до 1100 C.

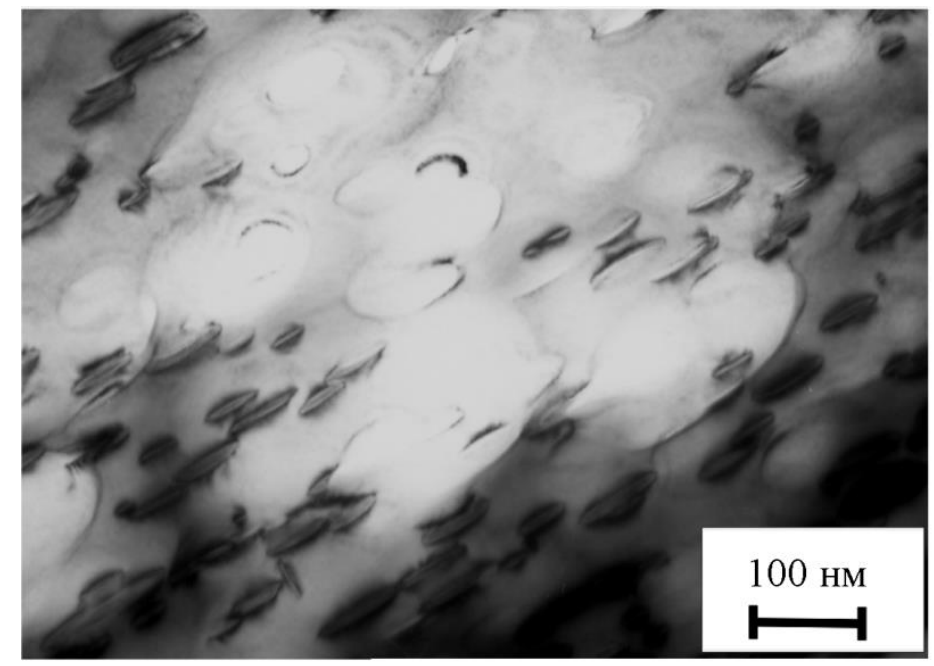

$a$

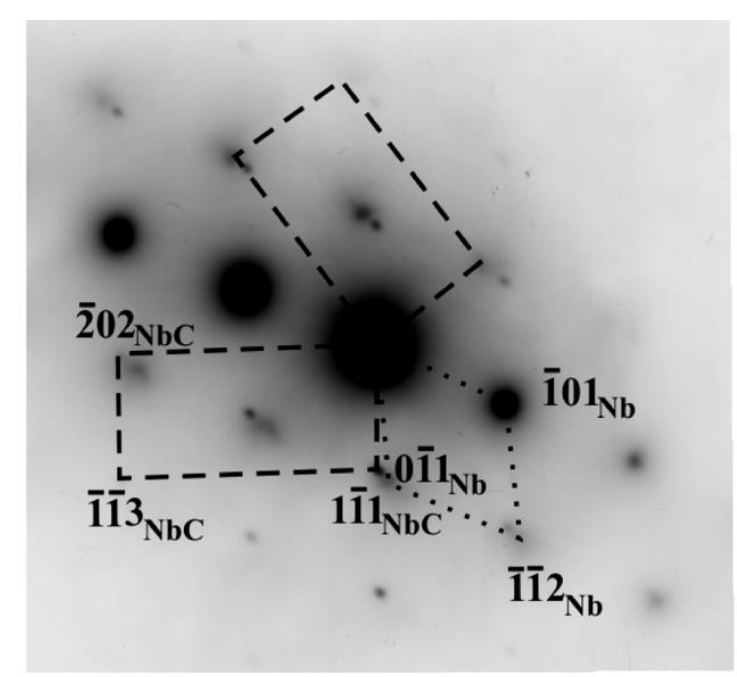

$\sigma$

Рис. 3. Структура ( $a$ ) и микродифракция (б) сплава ЛН-1 после термоупрочнения по схеме: отжиг при $1150{ }^{\circ} \mathrm{C}+\mathrm{OTP}+$ закалка + старение $\left(1000{ }^{\circ} \mathrm{C}, 5\right.$ ч $+1200{ }^{\circ} \mathrm{C}, 5$ ч); $a$ - светлопольное изображение; $\sigma$ - картина микродифракции, ось зоны $(001)_{\mathrm{Nb}}$

Сплав ТC6 (Ti-10,5Cr-7V-4Mo-3Al-1Zr) после закалки от температуры $800{ }^{\circ} \mathrm{C}$ с использованием скоростного электроконтактного нагрева имеет преобладающую рекристаллизованную структуру со средним размером $\beta$-зерен 26,3 мкм. Сплав с подобной частично рекристаллизованной структурой обладает следующим комплексом механических свойств: временное сопротивление $\sigma_{\mathrm{B}}=1030 \mathrm{MПа}$, условный предел текучести $\sigma_{0,2}=958$ МПа, относительное удлинение $\delta=5 \%$, относительное сужение $\psi=58 \%$. Анализ кривых деформациянапряжение при испытании образцов на растяжение показывает близость значений временного сопротивления, пределов текучести и пропорциональности при достаточно высоких значениях пластических характеристик. Аналогичные результаты были получены в ряде работ, посвященных термоупрочнению $\beta$ - и псевдо $\beta$-титановых сплавов $[11,12]$.

Как показали исследования с помощью световой микроскопии, в сплаве ТС6 в результате холодного волочения рекристаллизованное зерно вытягивается в направлении волочения, внутри зерен выявляются многочисленные следы сдвиговой деформации по различным плоскостям скольжения $\beta$-фазы с ОЦК решеткой. При деформации $\varepsilon=24 \%$ размер зерна в направлении волочения достигает 231 мкм. В результате холодной деформации сплав ТС6 упрочняется. При суммарной степени деформации $\varepsilon=24 \%$ прочностные и упругие характеристики возрастают. Суммарная деформация $\varepsilon=60-75 \%$ приводит к увеличению временного сопротивления до значений $\sigma_{\mathrm{B}}=1400$ МПа. Такой характер упрочнения обусловлен возрастанием плотности дислокаций. Как показали электронно-микроскопические исследования (рис. 4), в сплаве ТС6 после холодного волочения со степенями деформации $\varepsilon=24,0 \%$ внутри вытянутых в направлении волочения зёрен формируются полосовая структура с образоShaboldo O.P. et al. / Effect of thermomechanical treatment on the formation of the structure of high-strength $\mathrm{Nb}$ - and Ti-based alloys 
ванием дислокационных ячеек внутри полос. Размер дислокационных ячеек (светлые участки на рис. $4 a$ ) после деформации со степенью $\varepsilon=24,0 \%$ составляет $\sim 200 \times 400$ нм. С увеличением степени деформации до $\varepsilon=48,5 \%$ размер дислокационных ячеек уменьшается в несколько раз. При степенях деформации $\varepsilon=24,0$ и 48,5\% плотность дислокаций по границам ячеек достигает $5 \times 10^{10}$ и $7 \times 10^{10} \mathrm{~cm}^{-2}$ соответственно. На электронограмме от деформированного сплава ТС6 (рис. 4 б).

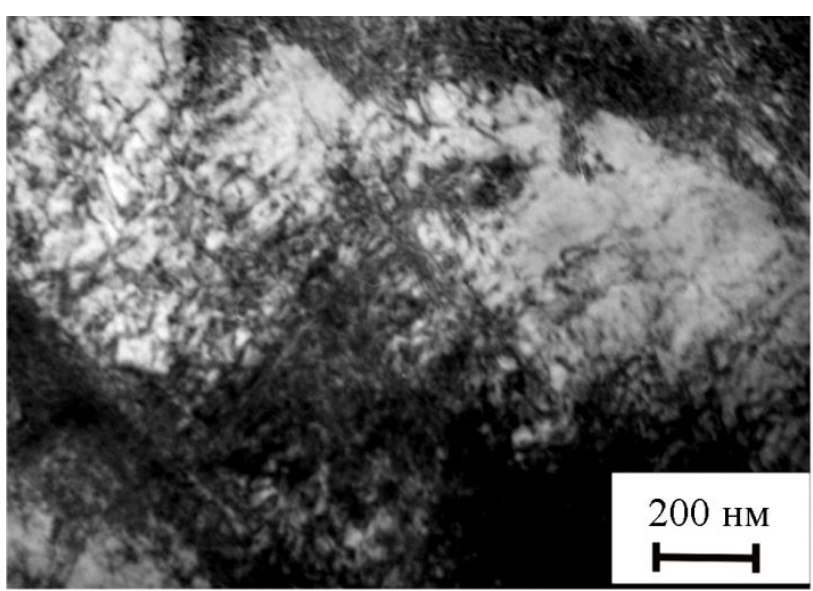

$a$

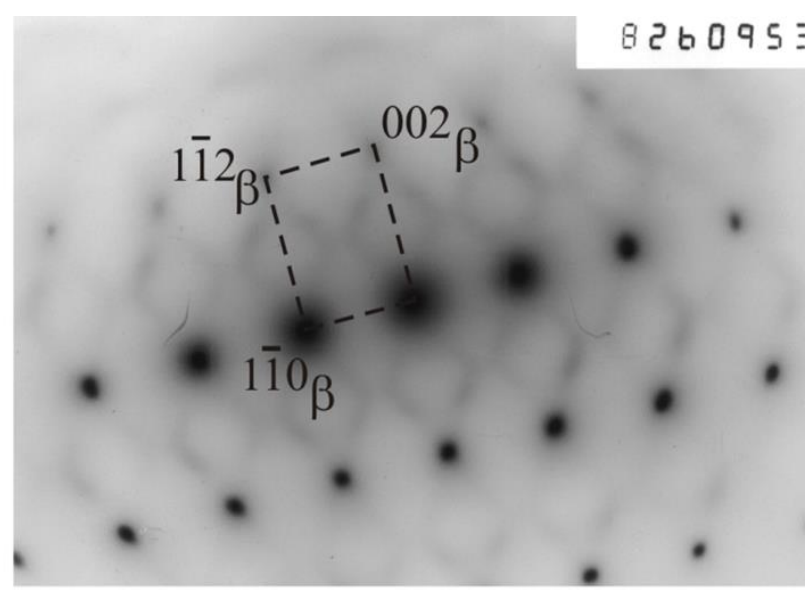

$\sigma$

Рис. 4. Дислокационная ячеисто-полосовая структура сплава ТС6 в $\beta$-состоянии после холодной деформации $\varepsilon=24 \%(a)$ и соответствующая электронограмма (б) с осью зоны [110] $\beta$-фазы титана присутствуют рефлексы только от $\beta$-фазы.

На рис. 5 представлены зависимости механических свойств деформированного ( $\varepsilon=24 \%)$ сплава ТС6 от продолжительности старения при температуре $450{ }^{\circ} \mathrm{C}$, при которой наблюдается выделение $\alpha$-фазы. Нагрев сплава ТС6 до $450{ }^{\circ} \mathrm{C}$ уже при выдержке 1 ч приводит к повышению прочности на 5-10 \%. Старение в течение 4 ч даёт прирост временного сопротивления на 275 МПа ( $22 \%)$. Характеристики пластичности составляют: $\delta=5,1 \%, \psi=24,0 \%$. С увеличением времени выдержки до 6-8 часов прочностные и упругие характеристики сплава возрастают до значений $\sigma_{\mathrm{B}}=1640 \mathrm{MПа,} \sigma_{0,2}=1545 \mathrm{MПа,} \sigma_{\text {пщ }}=1495$ МПа. Пластичность остается практически на том же уровне $(\delta=5,0 \%, \psi=22-23 \%)$. Незначительное снижение прочностных и упругих характеристик и одновременное повышение пластичности сплава при увеличении продолжительности старения до 10-12 часов связано, по-видимому, с коагуляцией частиц $\alpha$-фазы.

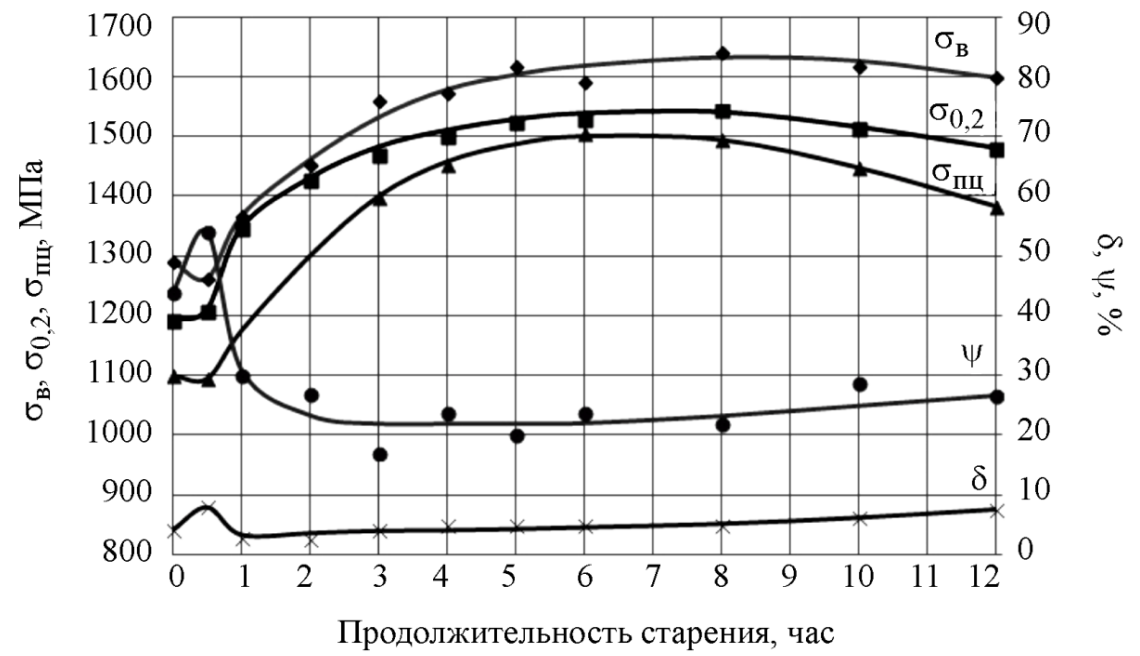

Рис. 5. Механические свойства сплава ТС6 после закалки от $800^{\circ} \mathrm{C}$, холодного волочения $(\varepsilon=24 \%)$ и разного времени старения при $450{ }^{\circ} \mathrm{C}$

Shaboldo O.P. et al. / Effect of thermomechanical treatment on the formation of the structure of high-strength $\mathrm{Nb}$ - and Ti-based alloys 
Высокий комплекс механических свойств деформированного сплава ТС6 после старения обусловлен особенностями распада $\beta$-фазы при $450{ }^{\circ} \mathrm{C}$. Световой микроскопией выявлено, что линии скольжения сплава ТС6 декорированы частицами дисперсной $\alpha$ фазы. При электронно-микроскопическом исследовании удается определить морфологию, расположение и решетку выделяющихся $\alpha$-частиц. На рис. $6 a$, $\sigma$ представлены структура и электронограмма сплава ТС6 после деформации $(\varepsilon=24 \%)$ и старения в течение 4 часов при температуре $450{ }^{\circ} \mathrm{C}$. На электронограмме (рис. 6 б) присутствуют только рефлексы $\alpha$ - и $\beta$ - фаз. Как видно из темнопольного изображения, выделившиеся кристаллы $\alpha$-фазы имеют форму пластин толщиной 10-30 нм и длиной 50-100 нм. Они располагаются в полосовой структуре по дислокационным границам ячеек и имеют плотность $5 \times 10^{15} \mathrm{~cm}^{-3}$ (внутри ячеек $\alpha$-фаза практически отсутствует). Преобладающая ориентация $\alpha$-пластин в соседних полосах почти одинаковая, что говорит о малой разориентации этих областей матричной $\beta$-фазы. Дисперсность $\alpha$-фазы и ее достаточно равномерное распределение, обусловленное распределением дислокаций, положительно отражается на механических свойствах сплава ТС6.

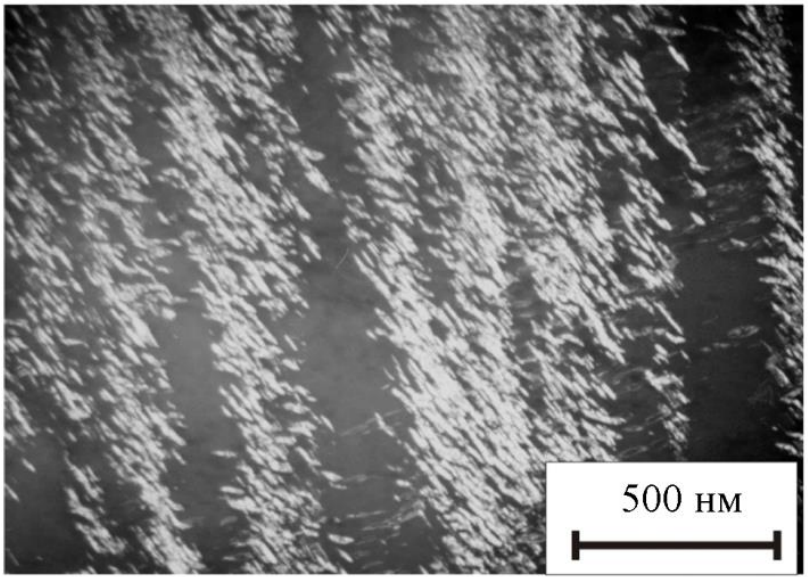

$a$

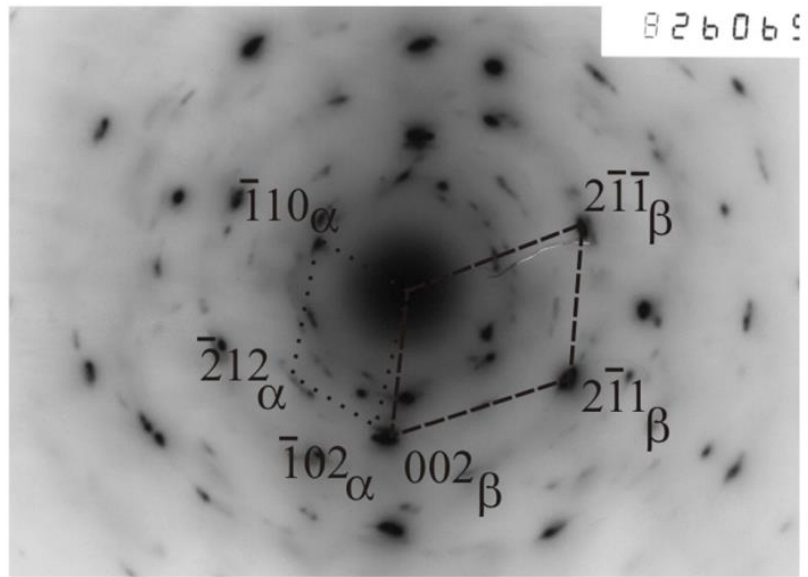

$\sigma$

Рис. 6. Темнопольное изображение упрочняющих частиц в рефлексе $(\overline{1} 10)_{\alpha}(a)$ и электронограмма (б) сплава ТС6 после закалки от $800{ }^{\circ} \mathrm{C}$, холодного волочения $(\varepsilon=24 \%)$ и старения при $450^{\circ} \mathrm{C}, 4$ ч. Оси зон фазы $[221]_{\alpha}$ и $[120]_{\beta}$

Как следует из рис. 4, в холоднотянутой со степенью деформации $\varepsilon=24,0$ \% проволоке в начале старения при температуре $450{ }^{\circ} \mathrm{C}$ (выдержка 0,5 часа) происходит незначительное снижение прочностных и упругих свойств сплава и повышение пластических характеристик. Это вызвано тем, что в сплаве при нагреве одновременно протекают два структурных процесса, влияющих противоположным способом на механические свойства: термический возврат и выделение упрочняющей $\alpha$-фазы. При выдержке 0,5 ч преобладают процессы дислокационного разупрочнения, при выдержке 1 ч уже наблюдается упрочнение сплава за счет распада $\beta$-фазы.

В недеформированном сплаве ТС6 после закалки от температуры рекристаллизации $\left(800^{\circ} \mathrm{C}\right)$ и старения повышение прочности материала с увеличением продолжительности старения происходит менее интенсивно, чем в деформированном материале. Максимальный уровень прочностных свойств существенно ниже, чем при старении в деформированном состоянии.

Shaboldo O.P. et al. / Effect of thermomechanical treatment on the formation of the structure of high-strength $\mathrm{Nb}$ - and Ti-based alloys 


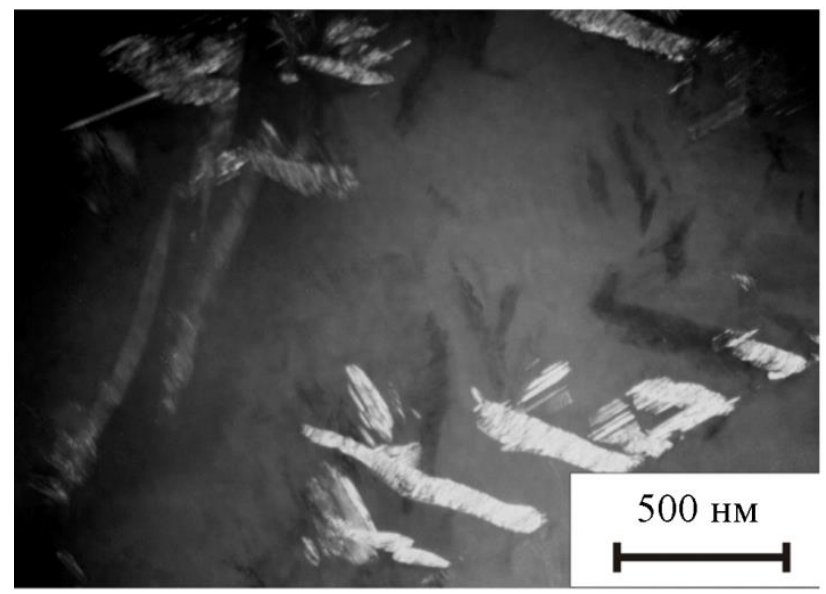

Рис. 7. Темнопольное (в пучке $101_{\alpha}$ ) изображение $\alpha$-фазы в сплаве ТС6 после старения в рекристаллизованном состоянии по режиму: $480{ }^{\circ} \mathrm{C}, 20$ ч

К изменению кинетики распада, динамики упрочнения и уменьшению уровня свойств сплава ТС6 приводит смена механизма зарождения $\alpha$-фазы при старении в рекристаллизованном состоянии (по сравнению со старением в деформированном материале). На рис. 7 представлено темнопольное (в рефлексе $\left.(101)_{\alpha}\right)$ изображение кристаллов $\alpha$-фазы, образующихся в результате старения при $480{ }^{\circ} \mathrm{C}, 20$ ч в предварительно закаленном сплаве ТС6. Как видно из приведенных структур, распад в рекристаллизованном зерне с очень малой плотностью дислокаций происходит, в основном, по механизму гомогенного зарождения $\alpha$-фазы. Уменьшение количества центров образования $\alpha$-фазы приводит к низкой плотности частиц $\left(6 \times 10^{13} \mathrm{~cm}^{-3}\right)$, а большая продолжительность старения - к увеличению размера частиц. Крупные частицы толщиной 30-70 нм и длиной 300-600 нм представляют собой набор из более тонких параллельных пластинок. Выделение крупных пластин малой плотности вполне объясняет умеренную прочность и низкую пластичность сплава после старения.

\section{4. Заключение}

1. Прослежена эволюция структуры и механических свойств жаропрочного сплава $\mathrm{Nb}-10 \mathrm{~W}-5 \mathrm{Mo}-1,5 \mathrm{Zr}-0,15 \mathrm{C}$ (ЛН-1) после теплой деформации и отжига при температурах 900-1550 ${ }^{\circ} \mathrm{C}$ с выдержкой 1 ч. При температурах $1200-1550{ }^{\circ} \mathrm{C}$ интенсифицируется насыщение сплава кислородом, приводящее к образованию фаз $\mathrm{ZrO}$ и $\mathrm{ZrO}_{2}$, снижающих жаропрочность сплава. Температура отжига $1150{ }^{\circ} \mathrm{C}(1$ ч), обеспечивающая достижение достаточно высокого уровня пластичности сплава $(\delta \sim 21 \%, \psi \sim 65 \%)$, позволяет выполнять деформирование образцов (в частности, навивку жаропрочных пружин) без образования поверхностных трещин.

2. Показано, что двухступенчатое старение $\left(1000^{\circ} \mathrm{C}, 5\right.$ ч $+1200^{\circ} \mathrm{C}, 5$ ч) закаленного от $1850{ }^{\circ} \mathrm{C}$ сплава $\mathrm{Nb}-10 \mathrm{~W}-5 \mathrm{Mo}-1,5 \mathrm{Zr}-0,15 \mathrm{C}$ (ЛН-1) приводит к благоприятному (для сохранения жаропрочности) гомогенному выделению дисперсных дископодобных частиц (NbZr)C толщиной менее 10 нм и диаметром 20-40 нм, если до закалки выполнен предварительный отжиг при температуре $1150{ }^{\circ} \mathrm{C}, 1$ ч, приводящий к выделению частиц типа $(\mathrm{NbZr}) \mathrm{C}$ и $\mathrm{Me}_{2} \mathrm{C}$.

3. В сплаве ТC6 $(\mathrm{Ti}-10,5 \mathrm{Cr}-7 \mathrm{~V}-4 \mathrm{Mo}-3 \mathrm{Al}-1 \mathrm{Zr})$ в результате скоростной закалки от температуры рекристаллизации $\left(800{ }^{\circ} \mathrm{C}\right)$ и холодной деформации $(\varepsilon=24 \%)$ формируется вытянутая ячеисто-полосовая структура с размерами ячеек $200 \times 400$ нм и высокой плотностью дислокаций $\left(\sim 5 \times 10^{10} \mathrm{~cm}^{-2}\right)$ по границам ячеек. В процессе последующего старения при $450{ }^{\circ} \mathrm{C}$ происходит распад $\beta$-фазы с гетерогенным выделением (на дислокациях) пластин $\alpha$-фазы толщиной 10-30 нм и длиной 50-100 нм. Малые размеры и высокая плотность $\alpha$-кристаллов

Shaboldo O.P. et al. / Effect of thermomechanical treatment on the formation of the structure of high-strength $\mathrm{Nb}$ - and Ti-based alloys 
$\left(5 \times 10^{15}\right.$ см$\left.^{-3}\right)$ обеспечивают существенное повышение прочностных характеристик сплава при сохранении удовлетворительных пластических свойств.

4. Смена гетерогенного механизма образования $\alpha$-фазы на гомогенный (в процессе распада $\beta$-фазы не в деформированном, а в закаленном сплаве ТС6 приводит к значительному укрупнению пластин $\alpha$-кристаллов и уменьшению их плотности $\left(6 \times 10^{13} \mathrm{~cm}^{-3}\right)$. Это обстоятельство вызывает существенное снижение максимально достижимых характеристик прочности в состаренном сплаве ТС6.

\section{Благодарность}

Электронно-микроскопические исследования проведены в ОЭМ ЦКП ИФМ УрО РАН в рамках государственного задания ФАНО России (тема «Структура», № 01201463331) и при частичной поддержке Уральского отделения РАН (проект № 15-9-2-16).

\section{Литература}

1. Шаболдо О. П., Виторский Я. М., Караштин Е. А. Пружинные материалы из жаропрочных сплавов на основе ниобия и никеля // ЦНИИ материалов - 100 лет на благо России. - Санкт-Петербург, 2012. - С. 125-136.

2. Пружинные материалы со специальными свойствами из труднодеформируемых высокопрочных высоколегированных термомеханически упрочняемых сплавов на основе титана, никеля и ниобия / О. П. Шаболдо, Я. М. Виторский, Е. А. Караштин, Е. В. Васильев, М. В. Сорокин // Металлообработка. - 2011. - Т. 62, № 2. - С. 28-35.

3. Савицкий Е. М., Дашевская О. Б. Дисперсионное упрочнение в сплавах на основе ниобия // Известия АН СССР. Металлы. - 1967. - № 3. - С. 152-158.

4. Бернштейн М. Л. Термомеханическая обработка металлов и сплавов. - М. : Металлургия, 1968. - 596 с. - Т. 1.

5. Хорев А. И. Создание теории термической, термомеханической обработок и текстурного упрочнения перспективных титановых сплавов // Материаловедение. - 2009. - № 4. C. 28-36.

6. Шаболдо О. П., Виторский Я. М., Караштин Е. А. Создание пружинного материала на основе высокопрочного титанового $\beta$-сплава марки ТС6 // ЦНИИ материалов - 100 лет на благо России. - Санкт-Петербург, 2012. - С. 158-168.

7. Titanium in Automotive Applications - Nightmare, Vision or Reality / H. Friedrich, J. Kiese, H.-G. Haldenwanger, A. Stich // The 10th World Conference on Titanium, Hamburg, Germany, 13-18 July, 2003 : proceedings / editted by G. Liitjering and J. Albrecht. - Vol. V. - P. 3393-3402.

8. Kosaka Y., Faller K. Advance of beta titanium alloy TIMETAL LCB in automotive spring applications // Wire Journal International. - 2006. - Vol. 39, no. 4. - P. 87-93.

9. Konno T. J., Miura E., Tanaka A., Hanada S. A TEM study on the semicoherent precipitates in Nb-19 \% Mo alloy // Acta Materialia. - 2005. - Vol. 53. - P. 1783-1789. DOI: $10.1016 /$ j.actamat.2004.12.027.

10. Viswanadham R. K., Wert C. A. Precipitation from supersaturated Nb-C solid solutions // Metallurgical transactions. - 1974. - Vol. 5. - P. 123-126.

11. Rapid Heat Treatment of TIMETAL ${ }^{\mathrm{R}}$ LCB Alloy / O. M. Ivasishin, P. E. Markovsky, P. G. Allen, D. G. Б. Sawakin, Yu. V. Matviychuk // The Ninth World Conference on Titanium “Titanium' 99, Science and Technology", Saint-Petersburg, Russia, 7-11 June, 1999 : proceedings. - Saint-Petersburg : Central Research Institute of Structural Materials (CRISM) "PROMETEY", 1999. - Vol. I. - P. 505-512.

12. Bhattacharjee A., Vydehi A. J., Gogia A. K. Microstructure and tensile behavior of a low cost beta alloy // The Ninth World Conference on Titanium "Titanium' 99, Science and Technology”, Saint-Petersburg, Russia, 7-11 June, 1999 : proceedings. - Saint-Petersburg : Central Research Institute of Structural Materials (CRISM) "PROMETEY", 1999. - Vol. I. - P. 537-544.

Shaboldo O.P. et al. / Effect of thermomechanical treatment on the formation of the structure of high-strength $\mathrm{Nb}$ - and Ti-based alloys 